\title{
Corrosion Behavior of Ni-20Cr-18W-1Mo Superalloy in Supercritical Water
}

\author{
Jingqing Zhang $\cdot$ Rui Hu $\cdot$ Jian Wang $\cdot$ Jinshan Li
}

Received: 14 November 2013/Revised: 14 April 2014/Published online: 6 August 2014

(C) The Chinese Society for Metals and Springer-Verlag Berlin Heidelberg 2014

\begin{abstract}
The corrosion behavior of Ni-20Cr-18 W-1Mo superalloy in supercritical water $500{ }^{\circ} \mathrm{C} / 25 \mathrm{MPa}$ for $200 \mathrm{~h}$ is investigated using gravimetry, SEM/EDS, XPS, and TEM. The oxide films show a layered structure with Ni rich in the outer layer, and $\mathrm{Cr}$ rich in the inner layer, consisting of an outer $\mathrm{Ni}(\mathrm{OH})_{2}$ and $\mathrm{NiO}$ layer, including some $\mathrm{Cr}(\mathrm{OH})_{3}$, and an inner $\mathrm{Cr}_{2} \mathrm{O}_{3}, \mathrm{NiCr}_{2} \mathrm{O}_{4}$, and $\mathrm{WO}_{3}$ layer. Mo elements are not oxidized. The oxide films grow via a mixed mechanism, namely metal dissolution/oxide precipitation mechanism and solid-state growth mechanism. The effects of secondary and primary carbides on the weight-gain trend and oxide formation are discussed.
\end{abstract}

\section{KEY WORDS: Ni-20Cr-18 W-1Mo; Corrosion behavior; Corrosion mechanism; Supercritical water; Oxide film}

\section{Introduction}

The supercritical-water-cooled reactor (SCWR), as one of the most promising advanced reactor concepts for generation IV nuclear reactor program, has attracted increasing attention in recent years because of its high thermal efficiency and plant simplification compared to the current light water reactor [1]. Supercritical water (SCW) refers to water with the temperature and pressure above the critical point of water at $374{ }^{\circ} \mathrm{C}$ and $22.1 \mathrm{MPa}$. Steam and lowdensity SCW can dissolve gases like oxygen to complete miscibility. Depending upon what species are present and how much oxygen is present in the solution, SCW in this state can become a very aggressive oxidizing environment. This is the cause of concern for the corrosion susceptibility of the structural materials in the reactors [2]. As a result,

Available online at http://link.springer.com/journal/40195

J. Zhang $(\bowtie) \cdot$ R. Hu $\cdot$ J. Wang $\cdot$ J. Li

State Key Laboratory of Solidification Processing, Northwestern

Polytechnical University, Xi' an 710072, China

e-mail: zhangjingqing0320@126.com the corrosion behavior of candidate materials is needed to be studied in order to ensure the safety of the nuclear reactor systems. $\mathrm{Ni}-\mathrm{Cr}-\mathrm{Mo} / \mathrm{W}$ alloys have been considered as candidate materials for SCWR due to their combined good corrosion resistance and mechanical properties [2-4]. Corrosion resistance of the alloys is often controlled mainly by microstructure $[4,5]$. The secondary carbides such as Cr-rich $M_{23} \mathrm{C}_{6}$ precipitated at the grain boundaries have an obvious influence on the resistance to intergranular corrosion and stress corrosion cracking [6-8]. It is also reported that the primary inclusions can act as the initiation sites of pitting [9, 10], corrosion fatigue [11], and stress corrosion cracking [12]. Much attention has been paid to the corrosion behavior of potential materials for SCWR under long exposure time in SCW [3, 4, 13, 14]. However, the effect of carbides on the corrosion behavior of materials in SCW environment is rarely discussed. Ni-20Cr-18 W$1 \mathrm{Mo}$ is a nickel-based superalloy with high concentrations of $\mathrm{Cr}$ and $\mathrm{W}$, which has good mechanical properties and oxide resistance at high temperatures and could be employed in nuclear reactor as promising structural candidate material. In this alloy, primary $M_{6} \mathrm{C}$ is homogeneously dispersed throughout the grain structure. Besides, 


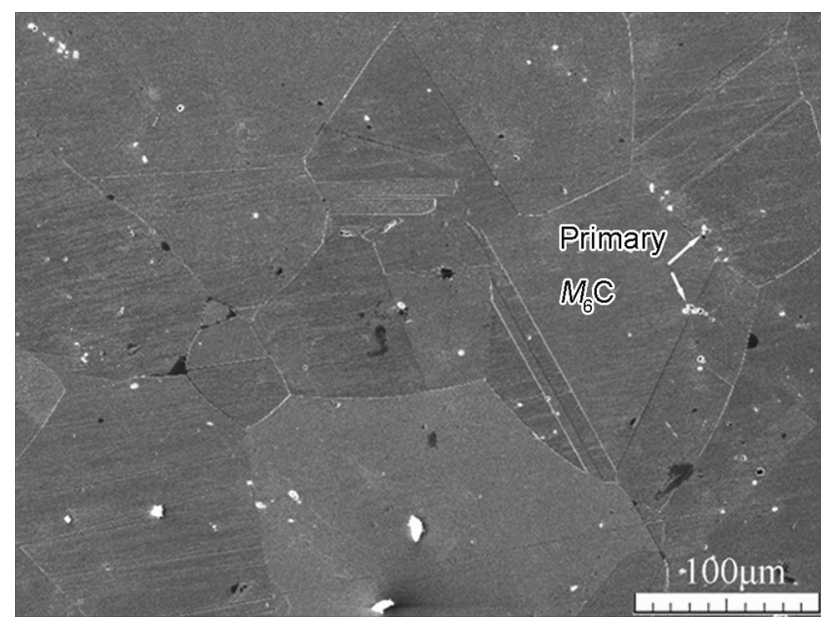

Fig. 1 The microstructure of $\mathrm{Ni}-20 \mathrm{Cr}-18 \mathrm{~W}-1 \mathrm{Mo}$ superalloy in annealed condition

when the alloy is aged at different temperatures, different secondary carbides will precipitate at the grain boundaries [15-17]. It can be speculated that these carbides have a close relationship with the corrosion behavior of the alloy.

The aim of the present work is to investigate corrosion performance of $\mathrm{Ni}-20 \mathrm{Cr}-18 \mathrm{~W}-1 \mathrm{Mo}$ superalloy exposed to $\mathrm{SCW}$ at $500{ }^{\circ} \mathrm{C}$ under a pressure of $25 \mathrm{MPa}$ and to characterize the morphologies, chemical composition, and phase composition of the oxide films formed on the surface of the alloy. The related corrosion mechanism and the effects of primary $M_{6} \mathrm{C}$ and secondary carbides on the corrosion behavior were discussed.

\section{Experimental}

The chemical composition (wt $\%$ ) of Ni-20Cr-18 W-1Mo superalloy is: Cr, 19.82; W, 18.48; Mo, 1.24; Al, 0.46; C, 0.11 ; B, 0.0028; La, 0.026; P, S < 0.004, Bal. Ni. The process for fabrication of the alloy is as follows. Initially, the cast material was vacuum induction melted and vacuum arc remelted. Then, the ingot was homogenized for $24 \mathrm{~h}$ at $1,200{ }^{\circ} \mathrm{C}$ and furnace cooled. Finally, it was hot forged and rolled at $1,050-1,150{ }^{\circ} \mathrm{C}$ into a sheet with a $9 \mathrm{~mm}$ thickness. The superalloy was cut into the samples with a dimension of $30 \mathrm{~mm} \times 20 \mathrm{~mm} \times 2 \mathrm{~mm}$ and solution treated at $1,280{ }^{\circ} \mathrm{C}$ for $0.5 \mathrm{~h}$, water quenched. The microstructure of the alloy in annealed condition is shown in Fig. 1. It can be seen that the average grain size is about $100 \mu \mathrm{m}$, primary $M_{6} \mathrm{C}$ particles are randomly dispersed throughout the grain structure and a number of twin boundaries are present, and these results have been reported also in the previous researches [16, 17]. Subsequently, the samples were aged at $700{ }^{\circ} \mathrm{C}$ for $2-72 \mathrm{~h}$ and
$600-1,100{ }^{\circ} \mathrm{C}$ for $10 \mathrm{~h}$, respectively. The samples for exposure test in SCW were mechanically ground progressively to $2000 \# \mathrm{SiC}$ emery paper, and then polished with $1.5 \mu \mathrm{m}$ diamond paste. Before the corrosion test, the samples were cleaned with acetone and ultrasonically rinsed with deionized water for $0.5 \mathrm{~h}$.

The samples were mounted on a rack and put into a GF5L nickel-based static autoclave at $500{ }^{\circ} \mathrm{C}$, under a pressure of $25 \mathrm{MPa}$ for exposure time up to $200 \mathrm{~h}$. After the exposure period, the samples were cleaned with deionized water and dried by a DHG-9053 oven. Then they were characterized by weight gain measurement, surface analysis, and cross-section analysis. The weight of all samples before and after the test was measured using a JA3003 electric balance with an accuracy of $0.1 \mathrm{mg}$. Three parallel specimens for every aging statement are used for SCW exposure tests. The oxide scale morphology, chemical composition, and cross-section morphologies as well as the microstructures of the samples were observed by a TESCAN MIRA3 XMU scanning electron microscope (SEM) equipped with an energy dispersive $\mathrm{X}$-ray spectroscope (EDS).Transmission electron microscopy (TEM, tecnai G2 F30) was used to identify the carbide phase precipitated at the grain boundaries. TEM samples were prepared by the twin-jet method in $8 \%$ perchloric acid carbinol solution at $-30{ }^{\circ} \mathrm{C}$. X-ray photoelectron spectroscopy (XPS) measurements were performed using ESCALAB 250Xi X-ray photoelectron spectrometer with an $\mathrm{Al} K \alpha$ radiation source operated at $150 \mathrm{~W}$ with initial photo energy $1486.6 \mathrm{eV}$. The elemental bonding was characterized as a function of depth in the oxidation scale and the depth profile information was performed over an area of $2.5 \mathrm{~mm} \times 2.5 \mathrm{~mm}$ under $2 \mathrm{keV} \mathrm{Ar}$ ion sputtering and the spectra was gained over a $0.5 \mathrm{~mm}$ spot. Ni $2 \mathrm{p}, \mathrm{Cr} 2 \mathrm{p}, \mathrm{W} 4 \mathrm{f}$, Mo $3 \mathrm{~d}$, and $\mathrm{O} 1 \mathrm{~s}$ core level spectra were recorded after different time $\mathrm{Ar}^{+}$ sputtering, and the peak decomposition was carried out with a peak fitting software (Avantage 5.52) using Gaussian/Lorentzian peak fitting after smart background subtraction to specify individual contributions of every element.

\section{Results}

\subsection{Weight Gain}

Figure 2 shows the weight gain of Ni-20Cr-18 W-1Mo superalloy exposed to SCW at $500{ }^{\circ} \mathrm{C} / 25 \mathrm{MPa}$ for $200 \mathrm{~h}$ as a function of aging temperature for $10 \mathrm{~h}$, and the weight gain of the samples as a function of aging time at $700{ }^{\circ} \mathrm{C}$ is shown in Fig. 3. It is observed from Fig. 2 that the weight gain reaches a minimum value at $700{ }^{\circ} \mathrm{C}$, and some fluctuations in weight gain appear from 800 to $1,100{ }^{\circ} \mathrm{C}$. It can 


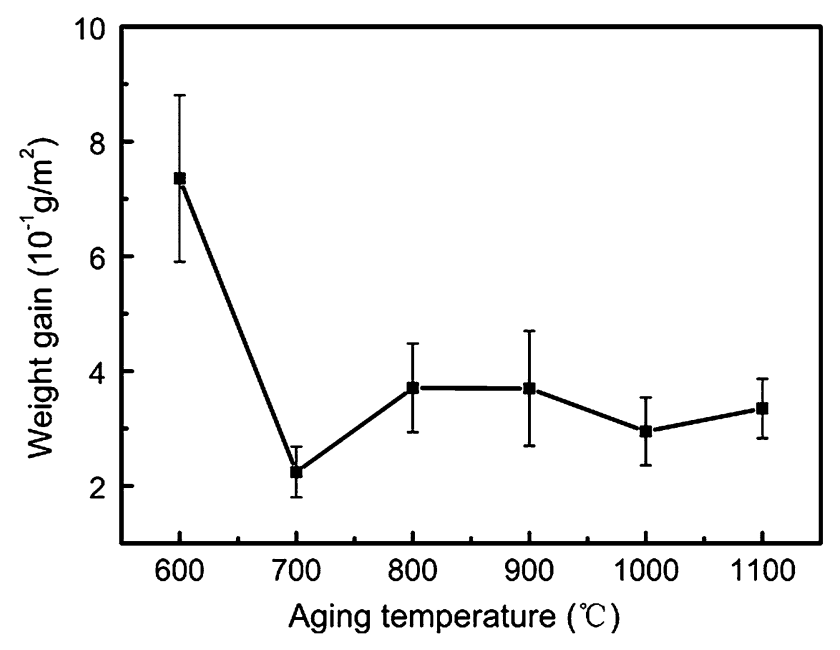

Fig. 2 Weight gain of Ni-20Cr-18 W-1Mo superalloy exposed to $\mathrm{SCW}$ at $500{ }^{\circ} \mathrm{C} / 25 \mathrm{MPa}$ for $200 \mathrm{~h}$ as a function of aging temperature for $10 \mathrm{~h}$

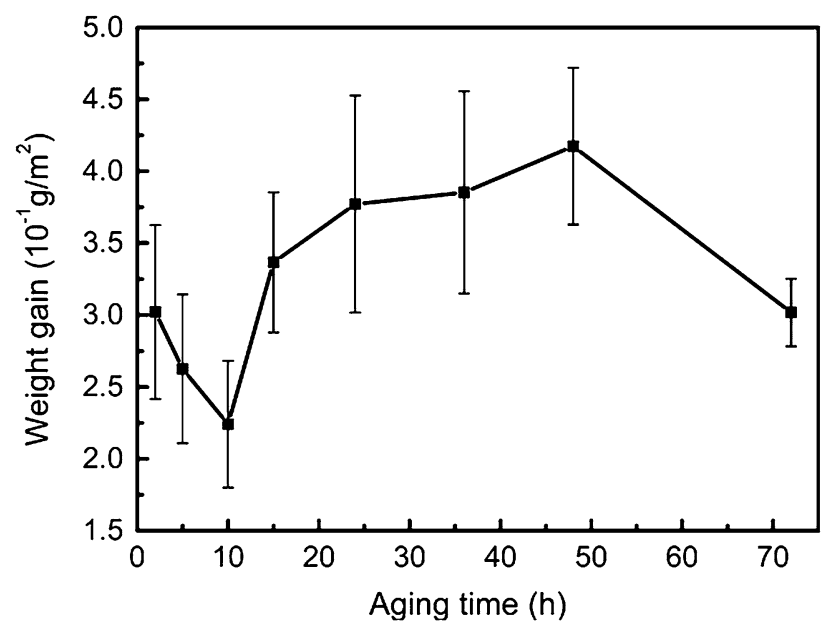

Fig. 3 Weight gain of Ni-20Cr-18 W-1Mo superalloy exposed to $\mathrm{SCW}$ at $500{ }^{\circ} \mathrm{C} / 25 \mathrm{MPa}$ for $200 \mathrm{~h}$ as a function of aging time at $700{ }^{\circ} \mathrm{C}$

be seen from Fig. 3 that the weight gain decreases first, and reaches a peak at $10 \mathrm{~h}$, and then increases with further aging time. A sudden weight loss is observed for the sample aged at $700{ }^{\circ} \mathrm{C}$ for $72 \mathrm{~h}$. Many previous works reported that the different trend was caused by the competition between weight gain due to oxidation and weight loss due to pitting or oxide dissolution [13, 14]. In the present work, since the samples are under different aging treatment conditions, the secondary carbide precipitation may play an important role in the oxidation process.

\subsection{Surface Morphology}

Figure 4 shows the effect of the aging temperature on the oxide film morphologies of the alloy. It can be seen that the oxide films seem to be layered oxide for all samples. The outer layer consists of large and irregular oxide particles, and the inner layer contains fine oxide particles. There are corrosion products around the primary $M_{6} \mathrm{C}$ and it can be seen from Fig. $4 \mathrm{~d}$ that primary $M_{6} \mathrm{C}$ is blacker than the matrix and tends to be broken down into pieces. It is indicated that the selective oxidation of the $M_{6} \mathrm{C}$ has occurred. The EDS analysis indicates that there is more $\mathrm{W}$ content in the corrosion products on or around the primary $M_{6} \mathrm{C}$ than those dispersed in the matrix (Table 1). The site " 1 " in Fig. 4d represents the oxide formed on or around the primary $M_{6} \mathrm{C}$ and site " 2 " represents the oxide dispersed in the matrix. It may have a close relationship with the chemical composition of $M_{6} \mathrm{C}$ which contains more W elements. Few cracks occur on the surface of some samples, as can be seen from Fig. 4a. The morphology of oxide film formed on the surface of the samples aged at $700{ }^{\circ} \mathrm{C}$ for different times is similar to that shown in Fig. 4, and the amount of the corrosion products is just different according to the corrosion degree which can be represented by the weight gain. Figure 5 shows the SEM morphologies of the oxide film on the sample aged at $700{ }^{\circ} \mathrm{C}$ for $48 \mathrm{~h}$ as a typical image of a sample oxidized in SCW. The network pattern (Fig. 5a) that can be seen is a sunken profile of the grain boundaries. It can be seen clearly from Fig. $5 b$ that the grain boundaries are almost free of oxide. It is also observed from Fig. 5c that the degree of corrosion is different between the grains on the two sides of twin grain boundaries. Although these phenomena are only shown in Fig. 5, they are valid for all the samples.

\subsection{Cross-section Analysis by SEM and EDS}

Figure 6 shows the cross-section morphologies of the oxide scales for the samples with different aging states, along with the corresponding chemical composition profile analysis by EDS. According to the morphology and elemental concentration distribution, the oxide film seems to be divided to two layers, consisting of a Ni-rich outer layer and a Cr-rich inner layer. $\mathrm{W}$ is also enriched in the inner layer. It can be deduced that the different distributions of these elements are related to the degree of oxidation progress and to their different affinities for oxygen and outward diffusion rates in the oxide scale. The depth profile of element distribution in oxide film formed on the sample is examined by XPS and the result is shown Fig. 6c. It be seen that the result is in accordance with that analyzed by EDS and it further confirms that the oxide film consists a $\mathrm{Ni}$-rich outer layer and a $\mathrm{Cr}$-rich inner layer. There is a primary $M_{6} \mathrm{C}$ free zone with a width about $100 \mu \mathrm{m}$ under the surface, which can be observed in Fig. 6d, this may be caused by the decomposition of $M_{6} \mathrm{C}$ during the oxidation progress since the primary $M_{6} \mathrm{C}$ precipitates homogeneously in the original sample before the corrosion process. 

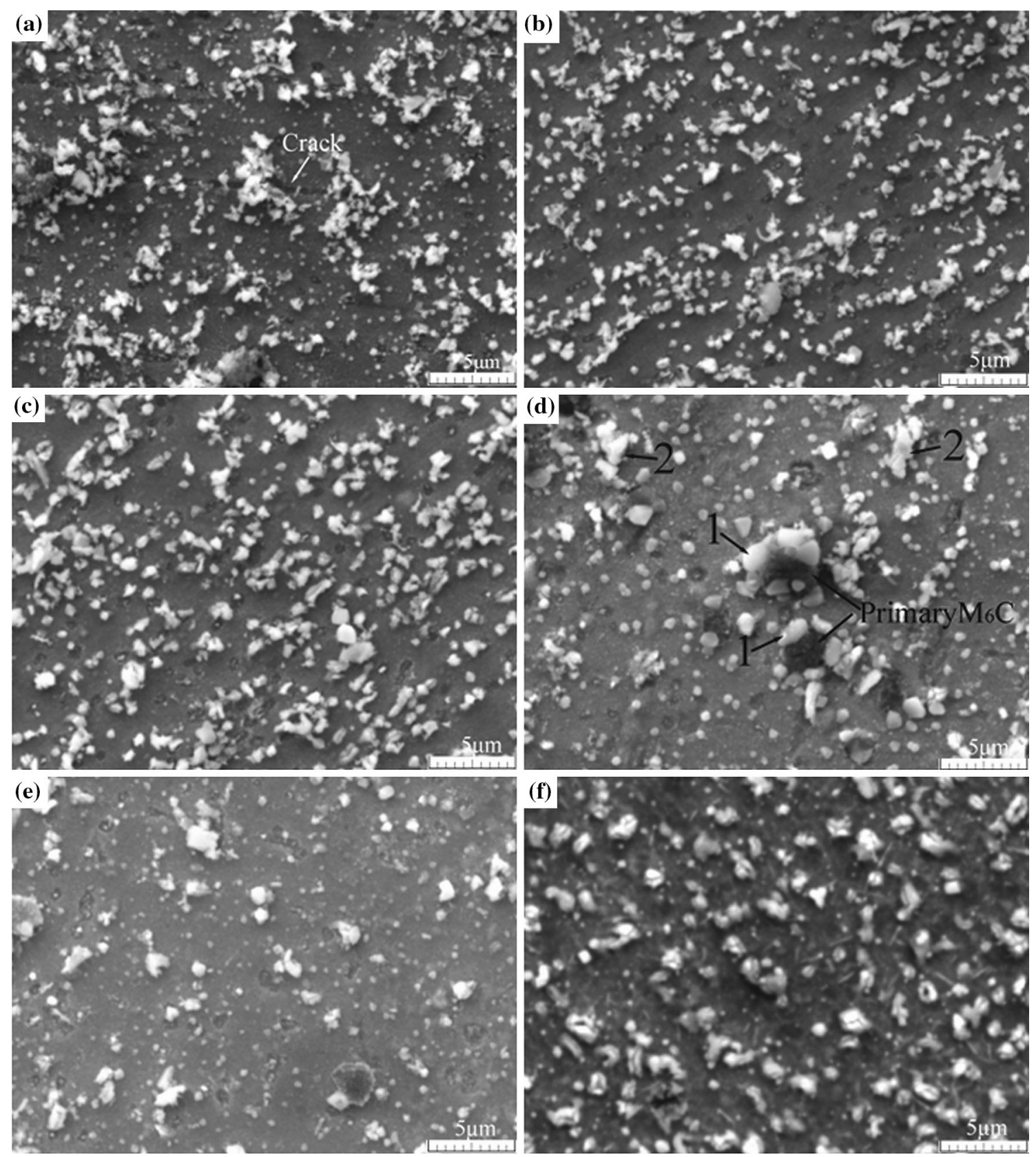

Fig. 4 SEM morphologies of the oxide film formed on the surface of the alloy aged at different temperatures for $10 \mathrm{~h}$ : a $600{ }^{\circ} \mathrm{C}, \mathbf{b} 700{ }^{\circ} \mathrm{C}$, c $800{ }^{\circ} \mathrm{C}, \mathbf{d} 900{ }^{\circ} \mathrm{C}$, e $1,000{ }^{\circ} \mathrm{C}, \mathbf{f} 1,100{ }^{\circ} \mathrm{C}$

\subsection{XPS Analysis}

The depth profile of the oxide film formed on the sample aged at $900{ }^{\circ} \mathrm{C}$ for $10 \mathrm{~h}$ was examined by XPS. Figure 7 shows the core level spectra of the five elements recorded after different sputtering times. The assignments for peaks are listed in the Tables 2, 3, 4, 5, and 6 according to the literatures [14, 18-24].

In the Ni $2 p$ core level spectra (Fig. 7a), for the outermost layer ( $0 \mathrm{~s}$ sputtering time), the peak is assigned to
$\mathrm{Ni}^{2+}$ in $\mathrm{NiO}$ and $\mathrm{Ni}(\mathrm{OH})_{2}$. After $30 \mathrm{~s}$ sputtering, the $\mathrm{Ni}$ $2 \mathrm{p}_{3 / 2}$ peak is decomposed into four components among which one located at the binding energy (BE) of $(852.82 \pm 0.04) \mathrm{eV}$, and its satellite peak at $(857.9 \pm 0.3)$ $\mathrm{eV}$. These two features originate from metallic $\mathrm{Ni}$, and the intensity of these peaks increases with increasing sputtering time. The metallic Ni peaks become dominant after $180 \mathrm{~s}$ sputtering. It is reported that the metallic $\mathrm{Ni}$ can result from two reasons: chemical reduction during ion sputtering or metal matrix $[14,21]$. Considering the 
Table 1 EDS results of sites 1 and 2 in Fig. 4d (wt \%)

\begin{tabular}{llrrl}
\hline Site & $\mathrm{Ni}$ & $\mathrm{Cr}$ & $\mathrm{W}$ & $\mathrm{O}$ \\
\hline 1 & 20.60 & 13.50 & 45.77 & 20.13 \\
2 & 66.74 & 8.78 & 9.62 & 14.86
\end{tabular}

Note site 1 represents the oxide formed on or around the primary $M_{6} \mathrm{C}$; site 2 represent the oxide dispersed in the matrix

intensity ratio of metallic $\mathrm{Ni}$, it is believed that the signal of metallic Ni comes from the chemical reduction when the sputtering time is no more than $360 \mathrm{~s}$, and the signal results from metal matrix after 690 and 1,290 s sputtering time. The $\mathrm{BE}$ of $854.9 \mathrm{eV}$ corresponding $\mathrm{NiO}$ or $\mathrm{Ni}(\mathrm{OH})_{2}$, and that of $(861.9 \pm 0.3) \quad \mathrm{eV}$ corresponding $\mathrm{NiCr}_{2} \mathrm{O}_{4}$ or $\mathrm{Ni}(\mathrm{OH})_{2}$. It can be seen form Fig. 7a that the intensity of the signal located at $\mathrm{BE}$ of $(861.9 \pm 0.3) \mathrm{eV}$ decreases first and then increases with sputtering time increasing. This results from the decrease of the signal of $\mathrm{Ni}(\mathrm{OH})_{2}$ and increase of that of $\mathrm{NiCr}_{2} \mathrm{O}_{4}$ with oxidation layer being peeled off. After $360 \mathrm{~s}$ sputtering time, the Ni 2p core level spectrums are similar to each other except for variations of peak height. The peaks have been decomposed into four components: one located at a BE originating from metallic $\mathrm{Ni}$, and its satellite peak, and the two other ones originate from $\mathrm{NiO}$ and $\mathrm{NiCr}_{2} \mathrm{O}_{4}$. The peaks located at the $\mathrm{Ni} 2 \mathrm{p}_{1 / 2}$ core level spectra have the same trend as that of $\mathrm{Ni} 2 \mathrm{p}_{3 / 2}$. According to above analysis, $\mathrm{NiO}$ and $\mathrm{Ni}(\mathrm{OH})_{2}$ exist on the outer layer of the oxide film and $\mathrm{NiCr}_{2} \mathrm{O}_{4}$ lays on the underlayer.

In the $\mathrm{Cr} 2 \mathrm{p}$ core level spectra (Fig. $7 b$ ), only one peak corresponding $\mathrm{Cr}(\mathrm{OH})_{3}$ occurs when the sputtering time is no more than $30 \mathrm{~s}$. After $180 \mathrm{~s}$ sputtering, the peaks of $\mathrm{Cr}^{3+}$ in $\mathrm{Cr}_{2} \mathrm{O}_{3}$ and $\mathrm{NiCr}_{2} \mathrm{O}_{4}$ appear as well as that of metallic Cr. After $360 \mathrm{~s}$ and $690 \mathrm{~s}$ sputtering time, the peaks are similar to that of $180 \mathrm{~s}$, and the peak of $\mathrm{Cr}_{2} \mathrm{O}_{3}$ is dominant. After $1,290 \mathrm{~s}$ sputtering, the peak of $\mathrm{NiCr}_{2} \mathrm{O}_{4}$ disappears and that of $\mathrm{Cr}$ is largely increased. The metallic $\mathrm{Cr}$ comes from the same way as that of metallic Ni. According to the above analysis, the oxidation scale of $\mathrm{Cr}$ element contains three layers, consisting of an outermost $\mathrm{Cr}(\mathrm{OH})_{3}$ layer, a $\mathrm{Cr}_{2} \mathrm{O}_{3}$ and $\mathrm{NiCr}_{2} \mathrm{O}_{4}$ mixed middle layer and a $\mathrm{Cr}_{2} \mathrm{O}_{3}$ inner layer.

In the $\mathrm{W} 4 \mathrm{f}$ core level spectra (Fig. 7c), the signal of the two peaks at lowest $\mathrm{BE}$ is assigned to metallic $\mathrm{W}$ and the intensity increases after $180 \mathrm{~s}$ with increasing sputtering time. The intensity of the peaks, corresponding $\mathrm{WO}_{3}$, has the same trend as that of metallic $\mathrm{W}$, which indicates that $\mathrm{WO}_{3}$ exists in the inner layer of the oxide film. The two peaks located at the highest $\mathrm{BE}$ of $(41.9 \pm 0.1)$ and $(44 \pm 0.1) \mathrm{eV}$ are present all the time during the sputtering, however, we cannot find the phases corresponding these peaks according to the published data. It can be speculated that these two peaks mostly originate from primary $M_{6} \mathrm{C}$. It can be seen from the surface morphology (Fig. 4d) that large primary $M_{6} \mathrm{C}$ particles exist on the surface of the alloy.

In the Mo 3d core level spectra (Fig. 7d), no peaks are observed after 0 and $30 \mathrm{~s}$ sputtering. After $180 \mathrm{~s}$ sputtering, the metallic Mo peaks appear, and the intensity of the peaks increases with increasing sputtering time. In the sputtering procedure, no peak assigned to the oxides appears, indicating that Mo is not oxidized which is in accordance with the cross-section analysis.

In the $\mathrm{O} 1 \mathrm{~s}$ core level spectra (Fig. 7e), the peaks have been decomposed into two components: one located at $\mathrm{BE}$ of $(530.5 \pm 0.2) \mathrm{eV}$, corresponding $\mathrm{O}^{2-}$ and the other one located at $(531.4 \pm 0.1) \mathrm{eV}$, corresponding $\mathrm{OH}^{-}$. With increasing sputtering time, the intensity of the signal at low $\mathrm{BE}$ increases, and that at high $\mathrm{BE}$ decreases, indicating that the outer layer of the oxide film contains hydroxide.

\section{Discussion}

In the present study, the oxide films grown on $\mathrm{Ni}-20 \mathrm{Cr}-$ $18 \mathrm{~W}-1$ Mo superalloy in supercritical water is a layered structure, consisting of an outer layer with Ni-rich large and irregular oxide particles, and a Cr-rich inner layer, which can be distinguished through the chemical composition profile. Besides, the $\mathrm{W}$ has a low diffusivity, so it is retained and enriched in the inner layer which can be distinguished by the XPS analysis (Fig. 7c). Some needle-like oxides (Fig. 4f) form on the surface. Many researches [25, 26] have found that needle-like oxide formed on Nickelbased alloy corresponds to $\mathrm{Ni}(\mathrm{OH})_{2}$ according to its crystal structure. According to the XPS analysis in the present study, the $\mathrm{Ni}^{2+}$ signals at BEs of 856.07 and $874.37 \mathrm{eV}$ are assigned to $\mathrm{Ni}(\mathrm{OH})_{2}$, confirming the existence of $\mathrm{Ni}(\mathrm{OH})_{2}$. The coarse oxide particles on the surface are identified as $\mathrm{NiO}$ according to its chemical composition (site 2 in Table 1). The Cr-rich layer consists of $\mathrm{Cr}_{2} \mathrm{O}_{3}$ and $\mathrm{NiCr}_{2} \mathrm{O}_{4}$, which has been observed by many other authors in nickelbased alloys [14, 20, 22, 25]. As a result, the outer layer mainly consists of $\mathrm{NiO}, \mathrm{Ni}(\mathrm{OH})_{2}$ and some $\mathrm{Cr}(\mathrm{OH})_{3}$, and the inner layer consists of $\mathrm{Cr}_{2} \mathrm{O}_{3}$ and $\mathrm{NiCr}_{2} \mathrm{O}_{4}$, including $\mathrm{WO}_{3}$, in the present work.

Several mechanisms have been proposed to explain the oxide scales grown on the metal materials in SCW, such as solid-state growth mechanism and metal dissolution/oxide precipitation mechanism which are generally accepted [2628]. In this work, the microstructure studies and related analyses indicate that the growth of the oxide scale agrees with a mixed mechanism. At the beginning, $\mathrm{Cr}$ is oxidized to form $\mathrm{Cr}_{2} \mathrm{O}_{3}$. Simultaneously, $\mathrm{Ni}$ and part of $\mathrm{Cr}$ can selectively dissolve into $\mathrm{SCW}$ at the active sites. The dissolved metal ions may combine with the anions to form 

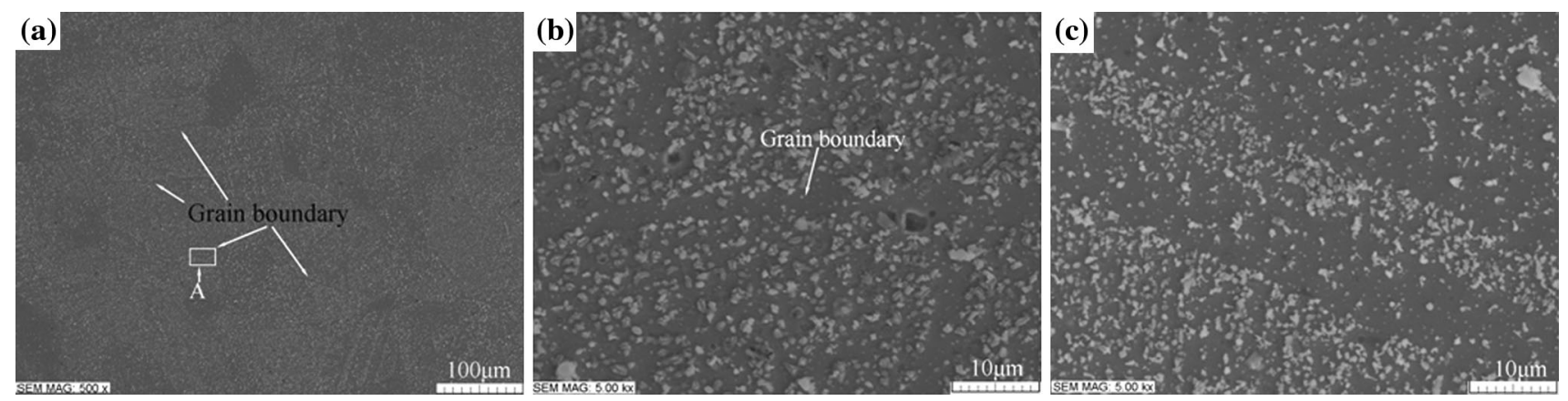

Fig. 5 SEM morphologies of the oxide film on the sample aged at $700{ }^{\circ} \mathrm{C}$ for $48 \mathrm{~h}$ : a low magnification, $\mathbf{b}$ high magnification image of area A in a, $\mathbf{c}$ high magnification image of areas from the two sides of twin grain boundaries
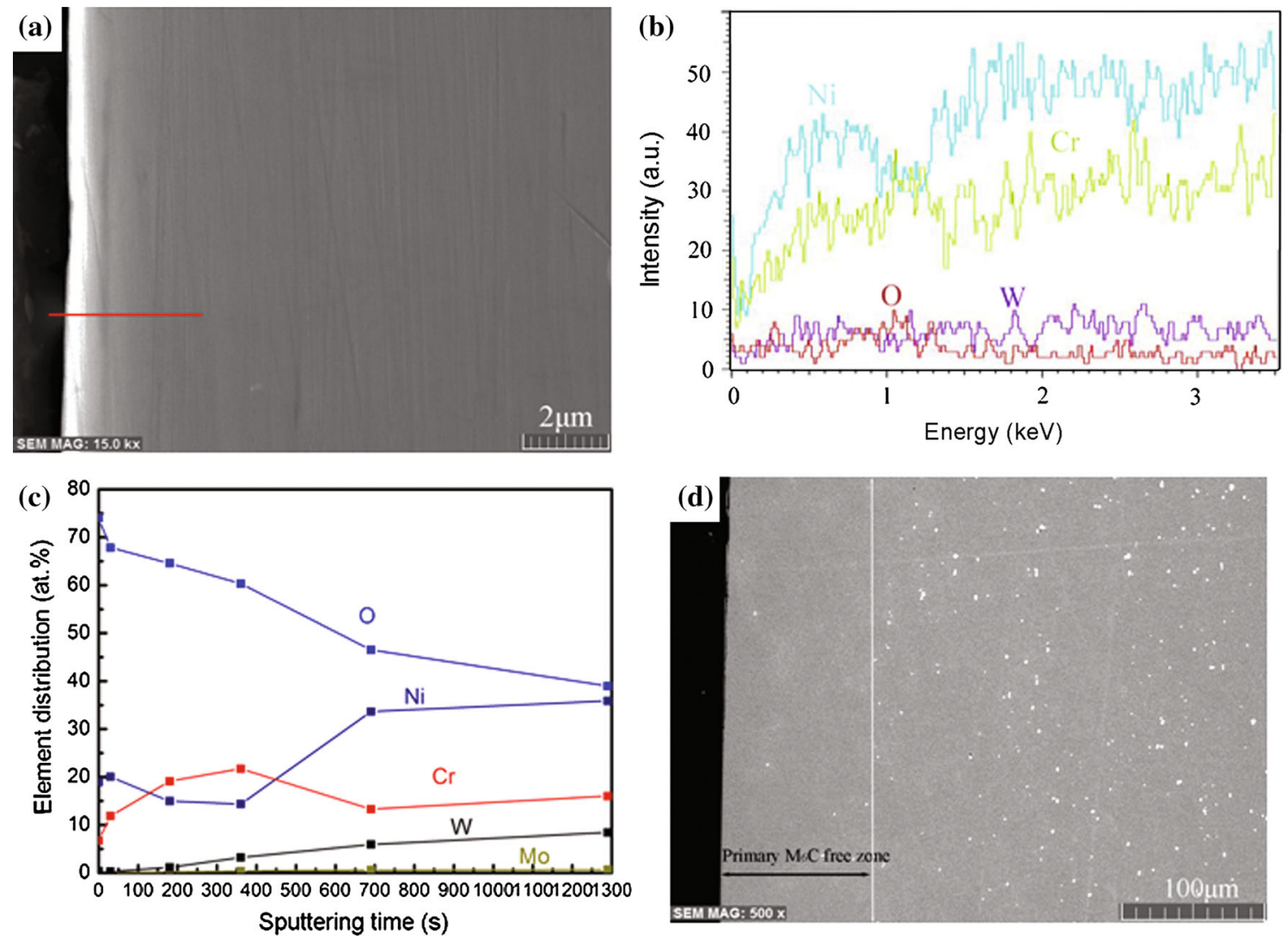

Fig. 6 SEM morphologies and EDS line scan analysis of the oxide films on the cross-section with different aging states: a SEM morphologies of the cross-section aged at $600{ }^{\circ} \mathrm{C}$ for $10 \mathrm{~h}$, b EDS line scan analysis for the sample in $\mathbf{a}, \mathbf{c}$ the depth profile of elements distribution of the oxide film analyzed by XPS for the sample in a, $\mathbf{d}$ aged at $700{ }^{\circ} \mathrm{C}$ for $48 \mathrm{~h}$

hydroxides or oxides and precipitate on the surface of the samples. $\mathrm{Cr}$ and $\mathrm{W}$ diffuse more slowly than $\mathrm{Ni}$ in the oxide $[13,29]$, so they are retained and enrich in the inner layer. Oxidation can continue by outward cation $\left(\mathrm{Ni}^{2+}\right)$ diffusion to the oxide/water interface and reaction with oxygen, and inward anion $\left(\mathrm{O}^{2-}\right)$ diffusion to the oxide/ substrate interface and reaction with enriched $\mathrm{Cr}$ and $\mathrm{W}$, resulting in forming an outer $\mathrm{NiO}$ layer and $\mathrm{Cr}_{2} \mathrm{O}_{3}$ inner layer. With the development of oxidation process, some $\mathrm{NiO}$ react with $\mathrm{Cr}_{2} \mathrm{O}_{3}$ to form $\mathrm{NiCr}_{2} \mathrm{O}_{4}$ in the inner layer. $\mathrm{W}$ may also diffuse into the lattice of $\mathrm{NiCr}_{2} \mathrm{O}_{4}$ as substitution.

The aging state of the samples may have a great influence on the oxidation process, since $\mathrm{Cr}$ - or $\mathrm{W}$-rich carbides will precipitate at the grain boundaries, which will affect the amount of the free ion in the matrix. Besides, the 

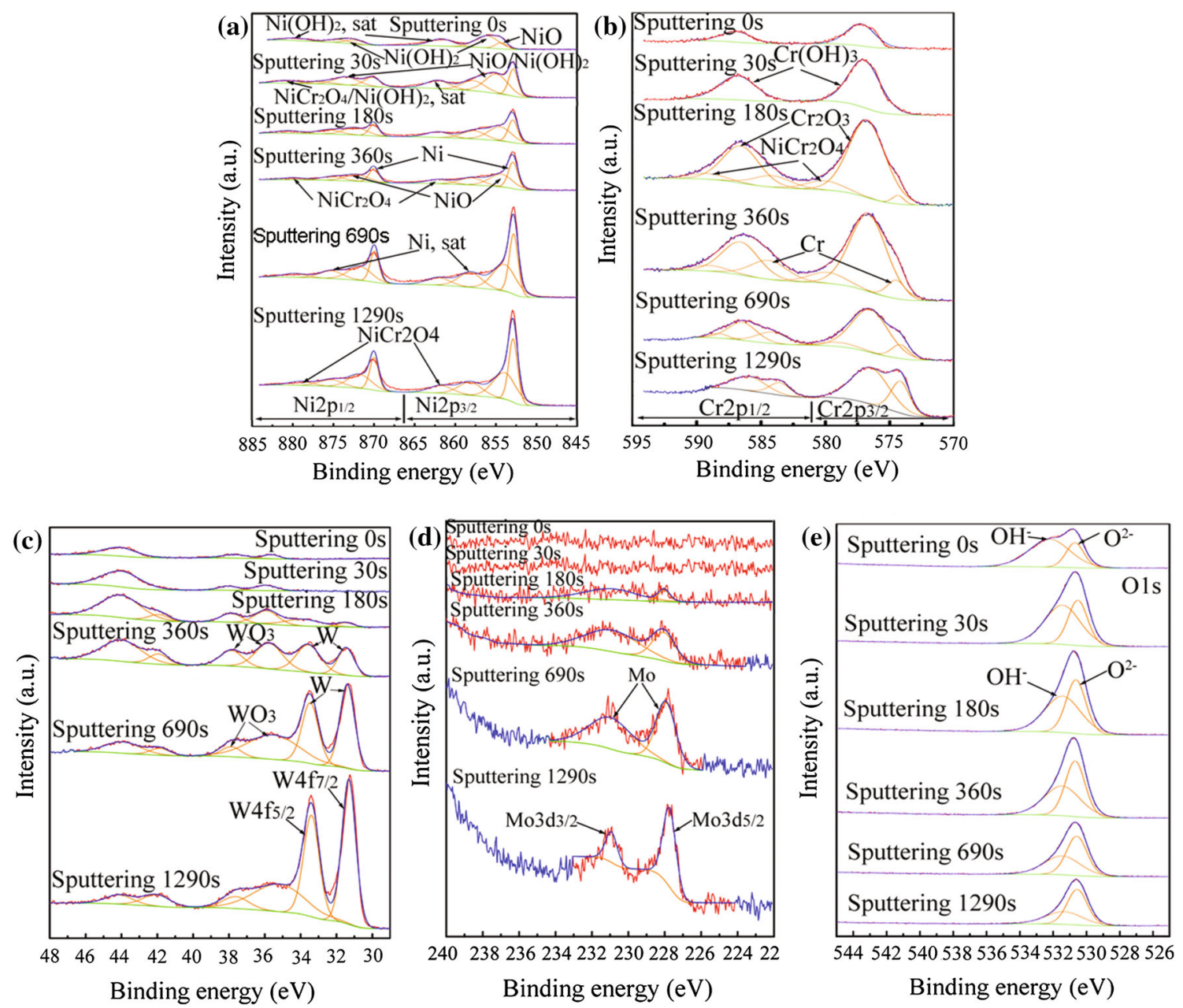

Fig. 7 XPS analysis of the SCW exposed sample aged at $900{ }^{\circ} \mathrm{C}$ for 10 h: a Ni 2 p core level spectra, b Cr 2 p core level spectra, c W 4 f core level spectra, d Mo 3d core level spectra, e $\mathrm{O} 1$ s core level spectra

Table 2 Assignments of Ni peaks in Fig. 7a

\begin{tabular}{llll}
\hline Element & $\mathrm{Ni}$ & & Component \\
\hline $\mathrm{BE}(\mathrm{eV})$ & $2 \mathrm{p}_{3 / 2}$ & $2 \mathrm{p}_{1 / 2}$ & \\
& $852.82 \pm 0.04$ & $870 \pm 0.15$ & $\mathrm{Ni}$ \\
& $857.9 \pm 0.25$ & $875.3 \pm 0.3$ & $\mathrm{Ni}, \mathrm{sat}$ \\
& $854.1 \pm 0.25$ & $872 \pm 0.3$ & $\mathrm{NiO}$ \\
& $861.9 \pm 0.3$ & $880 \pm 0.5$ & $\mathrm{NiCr} \mathrm{O}_{4} / \mathrm{Ni}(\mathrm{OH})_{2}, \mathrm{sat}$ \\
& 856.07 & 874.37 & $\mathrm{Ni}(\mathrm{OH})_{2}$ \\
& 854.9 & 873.37 & $\mathrm{NiO} / \mathrm{Ni}(\mathrm{OH})_{2}$ \\
\hline
\end{tabular}

oxidation is controlled by ion diffusion along the grain boundaries and defects in the scales [30].

When the Ni-20Cr-18 W-1Mo superalloy is aged at not higher than $800{ }^{\circ} \mathrm{C}$ and not lower than $650{ }^{\circ} \mathrm{C}$, lameller and $\mathrm{Cr}$-rich $M_{23} \mathrm{C}_{6}$ will precipitate at the grain boundaries [16]. Figure 8 shows the microstructure of samples aged at $700{ }^{\circ} \mathrm{C}$ for different times. It can be seen that the amount of $M_{23} \mathrm{C}_{6}$ increases with increasing aging time and reaches a maximum at $48 \mathrm{~h}$. Then, it decreases with aging time
Table 3 Assignments of $\mathrm{Cr}$ peaks in Fig. $7 \mathrm{~b}$

\begin{tabular}{llll}
\hline Element & $\mathrm{Cr}$ & & Component \\
\hline $\mathrm{BE}(\mathrm{eV})$ & $2 \mathrm{p}_{3 / 2}$ & $2 \mathrm{p}_{1 / 2}$ & \\
& $577.1 \pm 0.1$ & $586.9 \pm 0.1$ & $\mathrm{Cr}(\mathrm{OH})_{3}$ \\
& $576.6 \pm 0.1$ & $586.5 \pm 0.1$ & $\mathrm{Cr}_{2} \mathrm{O}_{3}$ \\
& $574.2 \pm 0.2$ & $584.1 \pm 0.3$ & $\mathrm{Cr}$ \\
& $579.9 \pm 0.2$ & $589.1 \pm 0.2$ & $\mathrm{NiCr}_{2} \mathrm{O}_{4}$ \\
\hline
\end{tabular}

Table 4 Assignments of W peaks in Fig. 7c

\begin{tabular}{llll}
\hline Element & $\mathrm{W}$ & & Component \\
\hline BE $(\mathrm{eV})$ & $4 \mathrm{f}_{7 / 2}$ & $4 \mathrm{f}_{5 / 2}$ & \\
& $31.4 \pm 0.1$ & $33.6 \pm 0.2$ & $\mathrm{~W}$ \\
& $35.7 \pm 0.3$ & $37.8 \pm 0.2$ & $\mathrm{WO}_{3}$ \\
& $41.9 \pm 0.1$ & $44 \pm 0.1$ & Primary $M_{6} \mathrm{C}$ \\
\hline
\end{tabular}

further increasing (Fig. 8h). There are a small amount of the carbides precipitated at the grain boundaries before $10 \mathrm{~h}$, and the width of the grain boundary is nearly the 
Table 5 Assignments of Mo peaks in Fig. 7d

\begin{tabular}{llll}
\hline Element & Mo & & Component \\
\hline BE $(\mathrm{eV})$ & $3 \mathrm{~d}_{5 / 2}$ & $3 \mathrm{~d}_{3 / 2}$ & \\
& $230.9 \pm 0.1$ & $227.9 \pm 0.2$ & Mo \\
\hline
\end{tabular}

same. So there are more free cations in matrix to be oxidized. The fewer the carbide is at the grain boundaries, the more cations provided for the oxidation process there are. So the weight gain decreases with increasing aging time (Fig. 3). As a result, the corrosion process is governed by the amount of free cations in matrix when the aging time is not more than $10 \mathrm{~h}$. For the sample aged at $15-48 \mathrm{~h}$, the amount of carbide increases largely and the width of the grain boundaries is widened obviously. Simultaneously, the interface between the carbide and matrix is increased. The free $\mathrm{Cr}$ content in the matrix decreases largely, so a protective oxide layer $\left(\mathrm{Cr}_{2} \mathrm{O}_{3}\right.$ layer $)$ is hard to form at the very beginning of oxidation. Besides, the wide grain boundaries and the increased interface between carbide and matrix provide an easy circuit diffusion of aggressive components such as oxygen penetrating into the metal matrix, as well as
Table 6 Assignments of $\mathrm{O}$ peaks in Fig. 7e

\begin{tabular}{lll}
\hline Element & $\mathrm{O}$ & Component \\
\hline $\mathrm{BE}(\mathrm{eV})$ & $1 \mathrm{~s}$ & \\
& $530.5 \pm 0.2$ & $\mathrm{O}^{2-}$ \\
& $531.4 \pm 0.1$ & $\mathrm{OH}^{-}$ \\
\hline
\end{tabular}

the metal elements diffusing outside. As a result, the weight gain increases all along. When the aging time increases to $72 \mathrm{~h}$, the amount of carbide decreases again resulting in a decrease in weight gain. As a result, the formation of protective oxide layer $\left(\mathrm{Cr}_{2} \mathrm{O}_{3}\right.$ layer $)$ at the very beginning of oxidation and the circuit diffusion of aggressive components and the metal element are the dominant factors that affect the corrosion process, and this is different from the samples aged at no more than $10 \mathrm{~h}$.

Figure 9 shows the microstructure of the samples aged at different temperatures for $10 \mathrm{~h}$. Table 7 shows the EDS analysis of primary $M_{6} \mathrm{C}$ carbide in the matrix and secondary carbide at the grain boundaries. It can be seen that there is no carbide precipitated at the grain boundaries at $600{ }^{\circ} \mathrm{C}$ and the carbide transforms from $\mathrm{Cr}$-rich lamellar to $\mathrm{W}$-rich particular
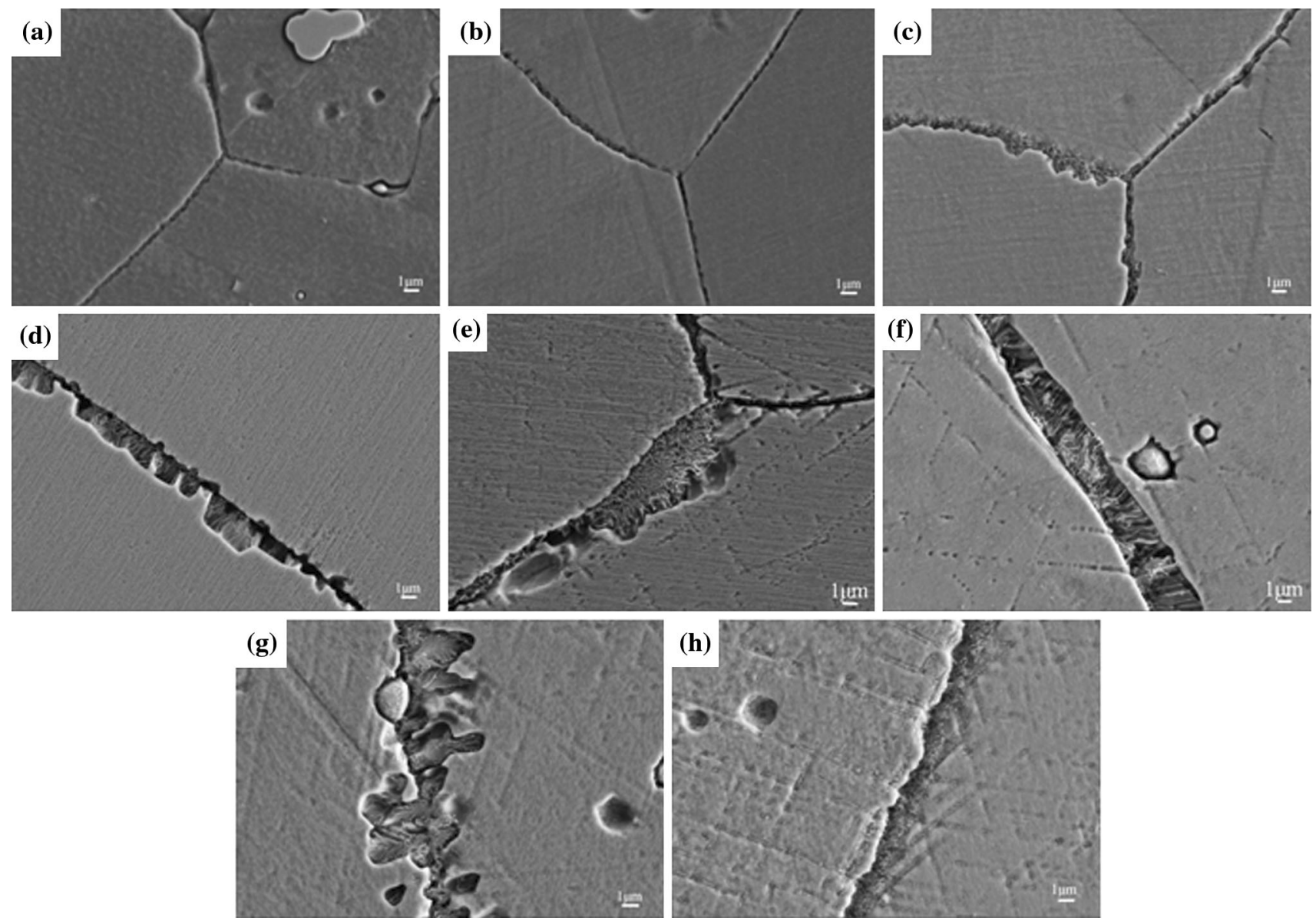

Fig. 8 The microstructures of the samples aged at $700{ }^{\circ} \mathrm{C}$ for different times: a $2 \mathrm{~h}, \mathbf{b} 5 \mathrm{~h}, \mathbf{c} 10 \mathrm{~h}, \mathbf{d} 15 \mathrm{~h}, \mathbf{e} 24 \mathrm{~h}, \mathbf{f} 36 \mathrm{~h}, \mathbf{g} 48 \mathrm{~h}, \mathbf{h} 72 \mathrm{~h}$ 

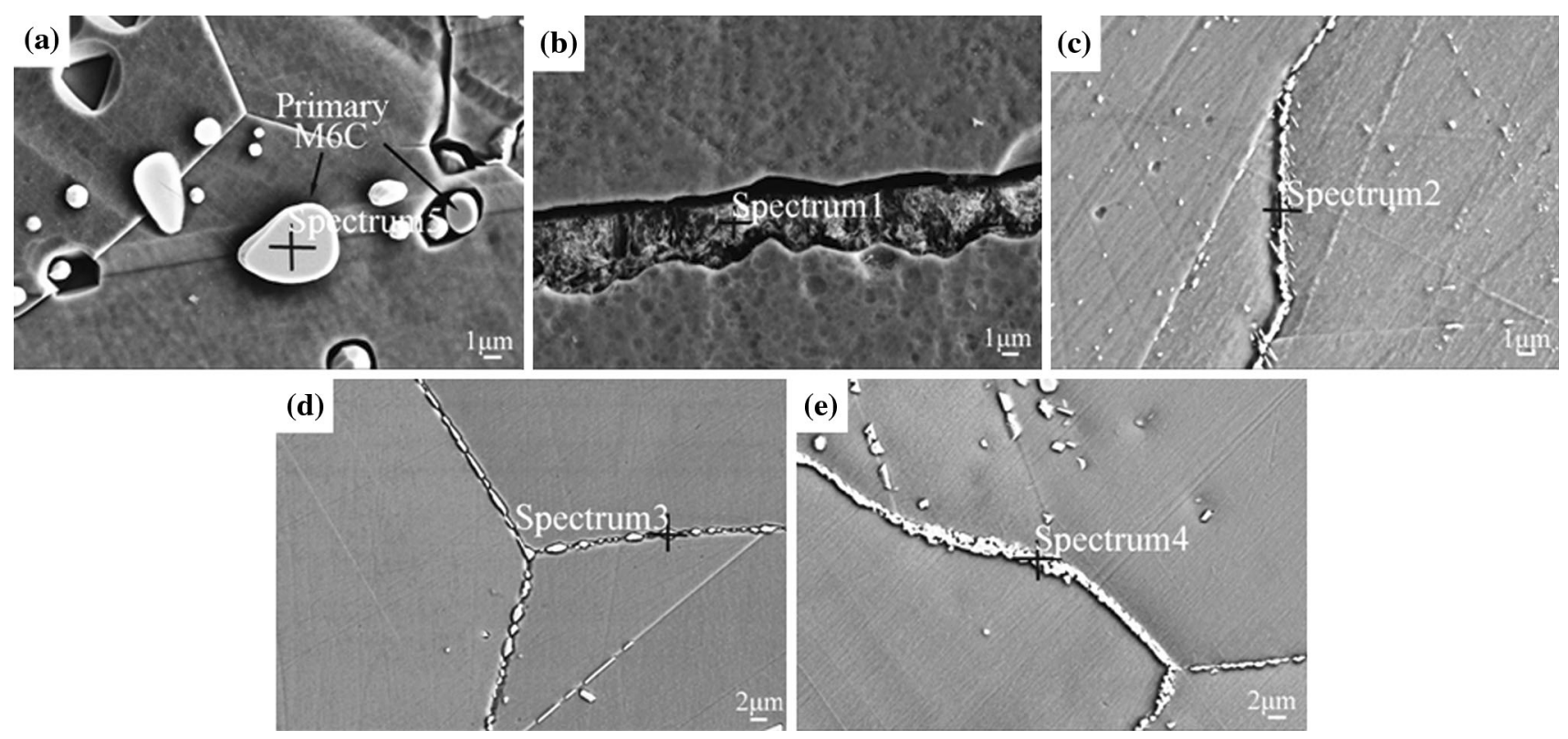

Fig. 9 The microstructures of the samples aged at different temperatures for $10 \mathrm{~h}$ : a $600{ }^{\circ} \mathrm{C}, \mathbf{b} 800{ }^{\circ} \mathrm{C}, \mathbf{c} 900{ }^{\circ} \mathrm{C}, \mathbf{d ~} 1,000{ }^{\circ} \mathrm{C}$, e $1,100{ }^{\circ} \mathrm{C}$

Table 7 EDS analysis of primary $M_{6} \mathrm{C}$ carbide and secondary carbide in Fig. 9 (wt\%)

\begin{tabular}{llrlll}
\hline Spectrum & Ni & \multicolumn{1}{l}{ Cr } & W & Mo & C \\
\hline Spectrum1 & 37.03 & 47.54 & 11.70 & 0.94 & 2.79 \\
Spectrum2 & 17.59 & 18.57 & 51.26 & 4.17 & 8.41 \\
Spectrum3 & 16.15 & 9.44 & 65.65 & 3.81 & 4.96 \\
Spectrum4 & 18.57 & 11.15 & 62.16 & 3.50 & 4.61 \\
Spectrum5 & 16.22 & 9.31 & 66.23 & 3.07 & 5.18 \\
\hline
\end{tabular}

with increasing aging temperature. When the aging temperature reaches to $1,000{ }^{\circ} \mathrm{C}$, the secondary carbide at the grain boundaries has the same composition as the primary $M_{6} \mathrm{C}$. TEM micrographs and typical [011] SAD patterns of the nonlamellar secondary carbides at the grain boundaries for the sample aged at $1,000{ }^{\circ} \mathrm{C}$ are shown in Fig. 10. The orientation relationship between the carbide and the matrix is ascertained to be $<011>$ carbide $/ /<011>$ matrix and $\{\overline{11} 1\}_{\text {carbide }} / /\{\overline{11} 1\}$ matrix. The lattice constant is calculated to be $1.133 \mathrm{~nm}$. The $\mathrm{W}$-rich carbide precipitated at the grain boundaries is identified as secondary $M_{6} \mathrm{C}$ according to the analysis [31]. As a result, it is Cr-rich $M_{23} \mathrm{C}_{6}$ as secondary carbide that precipitates at the grain boundaries when the sample is aged at not higher than $800{ }^{\circ} \mathrm{C}$, and when the sample is aged at not lower than $900{ }^{\circ} \mathrm{C}$, it is $\mathrm{W}$-rich $M_{6} \mathrm{C}$ as secondary carbide that precipitates at the grain boundaries. The previous research has proved the above result [32].

The trend of weight gain shown in Fig. 2 before $700{ }^{\circ} \mathrm{C}$ can be explained by the reason used in the duration of $2-10 \mathrm{~h}$ at $700{ }^{\circ} \mathrm{C}$. It is found that the weight change is fluctuated between 800 and $1,100{ }^{\circ} \mathrm{C}$. It is maybe caused by the balance among the several factors affecting the weight gain: (1) the amount of free cations in matrix; (2) the diffusion of elements along the grain boundaries and the interface between carbide and matrix which are affected by the morphology of secondary carbides precipitated at the grain boundaries; (3) the formation of protective $\mathrm{Cr}_{2} \mathrm{O}_{3}$ layer. The different secondary phases precipitated at the grain boundaries at different aging temperatures have an effect on the above factors due to the different chemical compositions and morphologies.

The difference of the oxidation degree between the two sides of twin grain boundaries (Fig. 5c) may be due to the different oxygen diffusion and adsorption characteristics between the grains because of the different orientations [33-36]. It is also found that the grain boundaries are almost free of oxide (Fig. 5b) compared with intragranular morphology, this is because $\mathrm{Ni}, \mathrm{Cr}$, and $\mathrm{W}$ react with carbon to form stable carbide at the grain boundaries during aging treatment, as a result, the elements will be hard to combine with anion when the samples are exposed to SCW. As for the twin grain boundary, it has a good resistance to oxidation and corrosion in nature [37].

In addition to the general oxidation, some selective oxidation of primary $M_{6} \mathrm{C}$ occurs (Fig. 4d). The EDS analysis indicates that the oxide on or around the primary $M_{6} \mathrm{C}$ contain more $\mathrm{W}$ than those dispersed in the matrix. It may have a close relationship with the chemical composition of $M_{6} \mathrm{C}$ which contains mainly W elements. During the oxidation, the primary $M_{6} \mathrm{C}$ can be decomposed and provide cations directly. The selective oxidation maybe caused by galvanic corrosion due to the difference of 

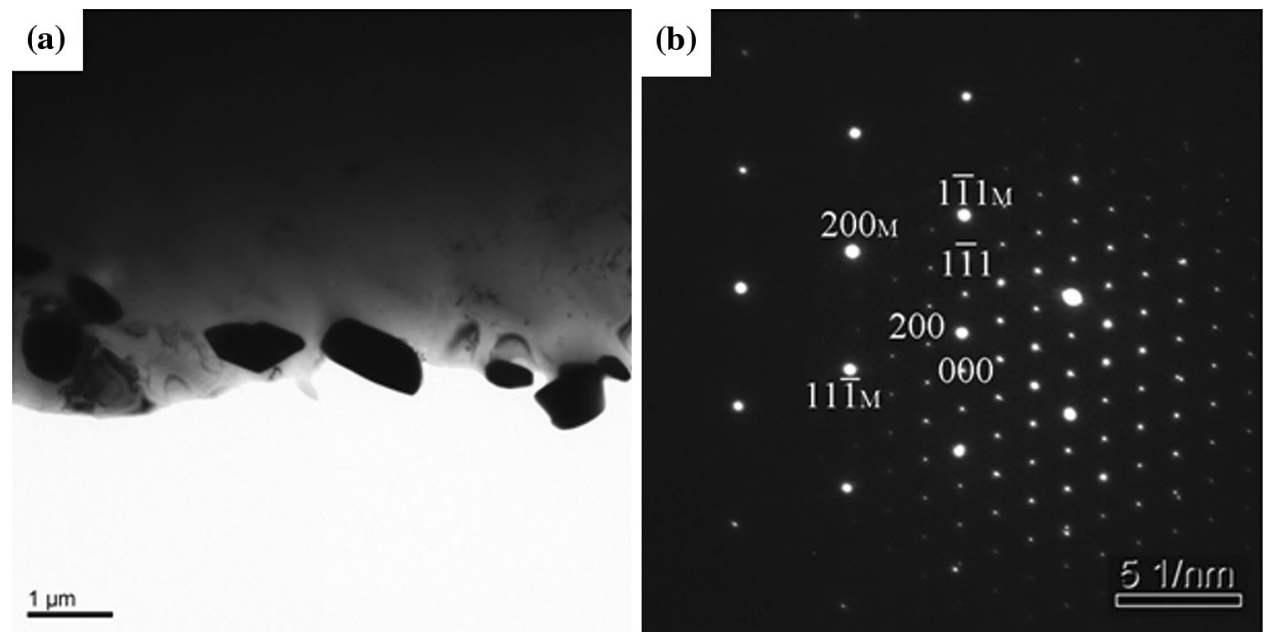

Fig. 10 TEM analysis of secondary carbides in the sample aged at $1,000{ }^{\circ} \mathrm{C}$ for $10 \mathrm{~h}$ : a BF micrograph of the carbide, $\mathbf{b}[011] \mathrm{SAD}$ pattern for a

electrochemical potential between the matrix and $\mathrm{W}$-rich primary $M_{6} \mathrm{C}[4,13]$.

The stress generation in the scale can cause oxide spallation. There are generally two types of stresses: growth stress caused by the oxide growth process, and thermal stress caused by the different thermal expansion between the oxide scale and the metal matrix during the heating and cooling process. The more oxide on the surface, the bigger the stress is originated from the growth stress, it can be seen from Fig. 4a that the coarse oxide cluster is collective, and there is few coarse oxide around the cluster, as a result, the growth stress dominates and cracks generate.

\section{Conclusions}

(1) The oxide scale formed on the $\mathrm{Ni}-20 \mathrm{Cr}-18 \mathrm{~W}-1 \mathrm{Mo}$ superalloy shows a layered structure, consisting of a $\mathrm{Cr}$-rich inner layer and Ni-rich outer layer grown via combined metal dissolution/oxide precipitation mechanism and solid-state growth mechanism. The outer layer consists of $\mathrm{Ni}(\mathrm{OH})_{2}, \mathrm{NiO}$, and some $\mathrm{Cr}(\mathrm{OH})_{3}$ and the inner layer contains $\mathrm{Cr}_{2} \mathrm{O}_{3}$ and $\mathrm{NiCr}_{2} \mathrm{O}_{4}$, including $\mathrm{WO}_{3}$.

(2) The secondary carbide precipitated at the grain boundaries can affect the weight-gain trend through influencing the amount of free cation in matrix, the state of the grain boundaries including the width of the grain boundaries and the interface between carbide and matrix, and protective $\mathrm{Cr}_{2} \mathrm{O}_{3}$ layer formation.

(3) The grain boundaries are almost free of oxidation due to the stable carbide formation which locks the elements and occupies the grain boundaries. The different degree of oxidation on the two sides of twin grain boundaries may be due to the different diffusion coefficient between two grains because of the orientation.

(4) During the oxidation process, the primary $M_{6} \mathrm{C}$ is decomposed and provides cations directly leading to a high $\mathrm{W}$ content in the oxide on or around the primary $M_{6} \mathrm{C}$ than those dispersed in the matrix.

Acknowledgments The authors are grateful to the financial support from the project supported by Research Fund of the State Key Laboratory of Solidification Processing, China (No. 62-TP-2011) and 111 project (No. B08040).

\section{References}

[1] G.S. Was, P. Ampornrat, G. Gupta, S. Teysseyre, E.A. West, T.R. Allen, K. Sridharan, L. Tan, Y. Chen, X. Ren, C. Pister, J. Nucl. Mater. 371, 176 (2007)

[2] C. Sun, R. Hui, W. Qu, S. Yick, Corros. Sci. 51, 2508 (2009)

[3] Q. Zhang, R. Tang, K. Yin, X. Luo, L.F. Zhang, Corros. Sci. 51, 2092 (2009)

[4] L. Tan, X. Ren, K. Sridharan, T.R. Allen, Corros. Sci. 50, 3056 (2008)

[5] M. Casales, V.M. Salinas-Bravo, A. Martinez-Villafañe, J.G. Gonzalez-Rodriguez, Mater. Sci. Eng. A 332, 223 (2002)

[6] T. Angeliu, G. Was, Mater. Trans. A 21, 2097 (1990)

[7] G. Sui, J.M. Titchmarsh, G.B. Heys, J. Congleton, Corros. Sci. 39, 565 (1997)

[8] Y.S. Lim, H.P. Kim, J.H. Han, J.S. Kim, H.S. Kwon, Corros. Sci. 43, 1321 (2001)

[9] Y. Lim, J. Suh, J. Kim, I. Kuk, Mater. Trans. A 28, 1223 (1997)

[10] Y.S. Lim, J.S. Kim, H.S. Kwon, J. Nucl. Mater. 336, 65 (2005)

[11] S. Xu, X. Wu, E.H. Han, W. Ke, Y. Katada, Mater. Sci. Eng. A 490, 16 (2008)

[12] F. Meng, J. Wang, E.H. Han, W. Ke, Corros. Sci. 52, 927 (2010)

[13] X. Ren, K. Sridharan, T.R. Allen, Corrosion 63, 603 (2007)

[14] X. Zhong, E.-H. Han, X. Wu, Corros. Sci. 66, 369 (2013) 
[15] R. Hu, G.H. Bai, J.S. Li, J.Q. Zhang, T.B. Zhang, H.Z. Fu, Mater. Sci. Eng. A 548, 83 (2012)

[16] G. Bai, R. Hu, J. Li, H. Zhong, H. Kou, H. Fu, Rare. Met. Mater. Eng. 38, 169 (2009). (in Chinese)

[17] G.H. Bai, J.S. Li, R. Hu, T.B. Zhang, H.C. Kou, H.Z. Fu, Mater. Sci. Eng. A 528, 2339 (2011)

[18] A. V. Naumkin, A. Kraut-Vass, S. W. Gaarenstroom, C. J. Powell, NIST X-ray Photoelectron Spectroscopy Database, NIST Standard Reference Database 20, Version 4.1, USA, 2012

[19] H. Sun, X. Wu, E.-H. Han, Corros. Sci. 51, 2840 (2009)

[20] H. Sun, X. Wu, E.-H. Han, Corros. Sci. 51, 2565 (2009)

[21] A. Machet, A. Galtayries, S. Zanna, L. Klein, V. Maurice, P. Jolivet, M. Foucault, P. Combrade, P. Scott, P. Marcus, Electrochim. Acta 49, 3957 (2004)

[22] T.M. Angeliu, G.S. Was, J. Electrochem. Soc. 140, 1877 (1993)

[23] J.F. Moulder, W.F. Stickle, P.E. Sobol, K.D. Bomben, Handbook X-ray Photoelectron Sprectroscopy (Perkin-Elmer, Eden Prairie, 1992)

[24] BE Lookup Table for Signal from Elements and Common Chemical, XPS International, Inc. 1999

[25] M. Sennour, L. Marchetti, F. Martin, S. Perrin, R. Molin, M. Pijolat, J. Nucl. Mater. 402, 147 (2010)
[26] Y. Yi, B. Lee, S. Kim, J. Jang, Mater. Sci. Eng. A 429, 161 (2006)

[27] M.C. Sun, X.Q. Wu, Z.E. Zhang, E.H. Han, J. Supercrit. Fluids 47, 309 (2008)

[28] X. Gao, X.Q. Wu, Z.E. Zhang, H. Guan, E.H. Han, J. Supercrit. Fluids 42, 157 (2007)

[29] R.E. Lobnig, H.P. Schmidt, K. Hennesen, H.J. Grabke, Oxid. Met. 37, 81 (1992)

[30] N.S. Mcintyre, D.G. Zetaruk, D. Owen, J. Electrochem. Soc. 126, 750 (1979)

[31] Q. Wu, H. Song, R.W. Swindeman, J.P. Shingledecker, V.K. Vasudevan, Metall. Mater. Trans. A 39, 2569 (2008)

[32] J.Q. Zhang, R. Hu, J. Wang, J.S. Li, J. Inno, Technol. Explor. Eng. 3, 48 (2013)

[33] R. Bès, S. Gavarini, N. Millard-Pinard, S. Cardinal, A. PerratMabilon, C. Peaucelle, T. Douillard, J. Nucl. Mater. 427, 415 (2012)

[34] M. Gillet, K. Mašek, C. Lemire, Thin Solid Films 444, 9 (2003)

[35] F. Czerwinski, J.A. Szpunar, Acta Mater. 46, 1403 (1998)

[36] P. Marikar, M.B. Brodsky, C.H. Sowers, N.J. Zaluzec, Ultramicroscopy 29, 247 (1989)

[37] B. Bennett, H.W.Pickering, Metall. Mater. Trans. A 18, 1117 (1987) 